\title{
Fruit and vegetable intake and bone mass in Chinese adolescents, young and postmenopausal women
}

\author{
Jing-Jing Li ${ }^{1}$, Zhen-Wu Huang ${ }^{2}$, Ruo-Qin Wang ${ }^{1}$, Xiao-Ming Ma ${ }^{1}$, Zhe-Qing Zhang ${ }^{1}$, \\ Zen Liu ${ }^{1}$, Yu-Ming Chen ${ }^{1, *}$ and Yi-Xiang Su, ${ }^{1, *}$ \\ 'Department of Medical Statistics \& Epidemiology, Guangdong Provincial Key Laboratory of Food, Nutrition and \\ Health, School of Public Health, Sun Yat-sen University, Guangzhou 510080, People's Republic of China: \\ ${ }^{2}$ Institute of Nutrition and Food Safety, Chinese Center for Disease Control and Prevention, Beijing, People's \\ Republic of China
}

Submitted 22 July 2011: Final revision received 22 February 2012: Accepted 6 March 2012: First published online 17 April 2012

\begin{abstract}
Objective: Previous studies showed an inconsistent association of fruit and vegetable consumption with bone health. We assessed the associations in Chinese adolescents, young and postmenopausal women.

Design: A cross-sectional study conducted in China during July 2009 to May 2010. Setting: Bone mineral density (BMD) and content (BMC) at the whole body, lumbar spine and left hip were measured with dual-energy X-ray absorptiometry. Dietary intakes were assessed using an FFQ. All these values were separately standardized into $Z$-scores in each population subgroup.

Subjects: One hundred and ten boys and 112 girls (11-14 years), 371 young women (20-34 years, postpartum within 2 weeks) and 333 postmenopausal women (50-70 years).

Results: After adjustment for potential covariates, analysis of covariance showed a significantly positive association between fruit intake and BMD and BMC in all participants combined ( $P$-trend: $<0 \cdot 001$ to $0 \cdot 002$ ). BMD $Z$-score increased by $0 \cdot 25$ (or $2 \cdot 1 \%$ of the mean), $0 \cdot 22(3 \cdot 5 \%), 0 \cdot 23(3 \cdot 0 \%)$ and $0 \cdot 25(3 \cdot 5 \%)$, and BMC $Z$-score increased by $0 \cdot 33(5 \cdot 7 \%), 0 \cdot 25(5 \cdot 8 \%), 0 \cdot 34(5 \cdot 9 \%)$ and $0 \cdot 29(4 \cdot 7 \%)$, at the total body, lumbar spine, total hip and femoral neck in participants belonging to the top tertile compared with the bottom tertile of fruit intake (all $P<0.05$ ), respectively. There was no significant association between vegetable intake and bone mass at all bone sites studied except for total body BMD $(P=0 \cdot 030)$. Relatively more pronounced effects were observed in boys and postmenopausal women.

Conclusion: Our findings add to the existing evidence that fruits and vegetables may have a bone sparing effect.
\end{abstract}

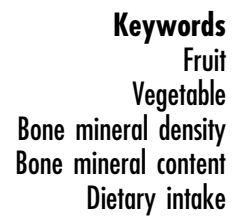

Osteoporosis is a major growing public health problem that affects one in three postmenopausal women and the majority of the elderly population ${ }^{(1)}$. It is affected by genetic, endocrine, mechanical, nutritional and other lifestyle factors or health behaviours, with extensive interactions between the different factors ${ }^{(2)}$. Nutritional factors are considered to be of particular importance to bone health because they are potentially modifiable ${ }^{(3)}$. Many studies have shown that some nutrients, such as alkaline ions $\left(\mathrm{K}^{+}\right.$and $\mathrm{Mg}^{2+}$ ), vitamin $\mathrm{K}$ and vitamin $\mathrm{C}$, found abundantly in fruit and vegetables, are associated with bone mass and urinary $\mathrm{Ca}$ excretion $^{(3,4)}$. These findings have led researchers to examine the linkages between fruit and vegetable consumption and bone health.
Many previous studies have examined the association between fruit and vegetable consumption and bone health as summarized in a recent review ${ }^{(4)}$. New et al. ${ }^{(5)}$ first reported the positive association of fruit and vegetable intake with bone mass in human populations. They found that bone mineral density (BMD) at the lumbar spine, femoral neck, trochanter and Ward's triangle was significantly lowered by $3 \cdot 4$ to $4 \cdot 8 \%$ in middle-aged (44-50 years) women who reported a low fruit intake in early adulthood compared with those who reported a medium or high intake. Similar positive associations between fruit and vegetable intake and BMD, bone mineral content (BMC) or lower fracture rates were also observed in most ${ }^{(6-10)}$, but not all ${ }^{(11)}$ studies. Therefore, the hypothesis of a beneficial effect of fruit and 
vegetables on bone health remains unclear ${ }^{(12)}$, and little is known about the effects of them in Asian populations who have traditionally consumed a plant-based diet.

Osteoporosis is determined by the storage of bone mass (or peak bone mass) accumulated before 30-35 years of age and the subsequent rate of bone loss. Adolescence, pregnancy and postmenopause are three important stages for bone health across the life cycle. During the 3-4 years of puberty in adolescents, BMD increases by about $50 \%$ and BMC by about $200 \%{ }^{(13)}$. Excess bone loss may occur among pregnant and lactating women because of substantial Ca transfers from them to their fetus or infant ${ }^{(14,15)}$. Increased rate of bone loss occurs in women after menopause due to rapidly declining concentrations of circulating oestrogen ${ }^{(16)}$. Therefore, it is important to assess the determinants of bone mass in these life stages.

Typical Chinese diets comprise higher components of vegetables, and lower intakes of protein, than their Western counterparts ${ }^{(17,18)}$. A Chinese national survey found a higher intake of fruit and vegetables $(320 \mathrm{~g} / \mathrm{d})$ among Chinese ${ }^{(18)}$ compared with American women at 52 years of age $(3.5(\text { SD } 1.8) \text { servings; } \sim 280 \mathrm{~g} / \mathrm{d})^{(19)}$. It is still uncertain whether greater fruit and vegetable intake is associated with better bone mass in Chinese populations ${ }^{(10)}$. The present cross-sectional study aimed to examine the associations between fruit and vegetable consumption and bone mass in adolescents, postpartum women and postmenopausal women.

\section{Participants and methods}

\section{Participants}

Participants included in the present cross-sectional study were composed of three age groups: (i) 222 early adolescent boys and girls aged 11-14 years; (ii) 371 parturient women (within 2 weeks postpartum) aged 20-34 years; and (iii) 333 postmenopausal women aged 50-70 years. The adolescent boys and girls were recruited from Year 1 students at four typical secondary schools in Guangzhou city in November 2009. Their parents were required to fill in a form for the study registration and eligibility screening. Potential adolescents were enrolled based on the returned registration forms. The parturient women (volunteers) were recruited from in-patients in Guangdong Women and Children's Hospital and Health Institute during July 2009 to May 2010, and the postmenopausal women were enrolled from communities in urban Guangzhou by local post between July and November 2009. The girls were required to have menarche, and the postmenopausal women to have natural menopause for at least 12 months. Exclusion criteria included hormonal replacement therapy, malabsorption, lactose intolerance, chronic liver or kidney diseases, parathyroid and thyroid diseases, gastric operation or cancer, oophorectomy and/or hysterectomy.
After initial screening for eligibility, we invited the potential participants to the Guangdong Women and Children's Hospital and Health Institute for face-to-face questionnaire interviews and measurements of bone mass and anthropometric indices after further confirming their eligibility. Written informed consent was obtained from all participants (or their legal guardians for the adolescents) prior to the final enrolment. The ethical committee of the School of Public Health of Sun Yat-sen University approved the study.

\section{Data collection}

Anthropometric and bone mineral status measurements Height was measured to the nearest $0 \cdot 1 \mathrm{~cm}$ and weight to the nearest $0 \cdot 1 \mathrm{~kg}$ with the participant in light clothing and no shoes standing motionless and straight in the centre of the scale. BMI was calculated as weight (in kilograms) divided by the square of height (in metres).

Dual-energy X-ray absorptiometry (DPX-L instrument; GE Lunar, Waukesha, WI, USA) was used to measure BMD $\left(\mathrm{g} / \mathrm{cm}^{2}\right)$ and BMC $(\mathrm{g})$ at the whole body, lumbar spine (L1-L4) and left hip (including total hip and femoral neck). The in vivo reproducibility of the machine was $1.92 \%, 1.48 \%$ and $0.68 \%$ for the BMD tests at the femoral neck, lumbar spine and whole body, respectively.

\section{General information and dietary assessments}

Face-to-face interviews based on a structured questionnaire were used to collect general information on sociodemographic data, years since menarche (for girls) or menopause (for postmenopausal women) and physical activities. The metabolic equivalent for task (MET) was calculated for daily physical activities.

The dietary assessment of intakes of fruit, vegetables, $\mathrm{Ca}$ and protein was based on a quantitative FFQ that included seventy-nine food groups/items as validated in previous studies $^{(20)}$. The mean intake of food per day, week or month was reported at the face-to-face interview, using the past 12 months (in postmenopausal women) or 3 months (in adolescents and parturient women) prior to the interview as the reference period. Food photographs in the reference portion sizes and some household measures used in the FFQ as serving size were provided for aids. Fruit intake was estimated based on ten main fruit items/groups: (i) orange, grapefruit and lemon; (ii) apple, pear, peach, pineapple and plum; (iii) banana; (iv) grapes; (v) lychee and longan; (vi) mango and persimmon; (vii) papaya; (viii) water melons and various muskmelons; (ix) durian; and (x) other fruits; Vegetable intake was estimated based on thirteen main vegetable groups/subgroups: (i) dark-green leafy vegetables (four subgroups, including nineteen common vegetables); (ii) light-green leafy vegetables (e.g. broccoli, cabbage, cauliflower, celery); (iii) onion, garlic; (iv) turnip and various vegetable melons (e.g. Chinese waxgourd, pumpkin, cucumber, towel gourd, bitter gourd, 
luffa-smooth loofah, eggplants); (v) tomato; (vi) peppers; (vii) carrots; (viii) starchy vegetables (e.g. yam and potato, taro, other tubers); (ix) fresh corn; (x) fresh beans; and (xi) mushrooms and edible fungi. Pickled vegetables were excluded in the calculation of vegetable intake. Dietary energy and nutrient intakes were calculated from the China Food Composition Table ${ }^{(21)}$. The correlation coefficients for the short-term reproducibility of fruit and vegetable intakes were $r=0.65(P<0.0001)$ and $r=0.58$ $(P<0 \cdot 0001)$, respectively, in the study participants.

\section{Statistical analyses}

We examined the associations between intake of vegetables, intake of fruit and total intake of fruit and vegetables with BMD and BMC among all participants combined due to limited sample size in each age and sex group. To ensure the comparability of the values for dietary intakes of fruit and vegetables, total energy, Ca and protein, BMD and BMC, BMI and MET of physical activity, these variables were separately standardized into normal $Z$-scores in each subgroup of girls, boys, young women and postmenopausal women. The $Z$-scores were then used in the following analyses. Participants were classified into tertiles according to the $Z$-score of fruit or vegetable intake in each of the four subgroups. One-way ANOVA and analysis of covariance were used to compare the mean difference between $Z$-scores of BMD and BMC among the fruit or vegetable tertiles. In the analysis of covariance we adjusted for age (years), BMI ( $Z$-score), dietary intakes ( $Z$-score) of energy, protein and $\mathrm{Ca}$, physical activity ( $Z$-score of MET), use of vitamin supplements (yes/no), use of Ca supplements (yes/no), sex and menopause status (yes/no). Pair-wise comparisons were done by the Bonferroni method. Multivariate regression was conducted to assess the independent associations between total intake of fruit and vegetables and BMD and BMC in each of the sex and age groups. The enter method was used for the intake of fruit and vegetables, and the stepwise method was used for the covariates of age (years), BMI ( $Z$-score), dietary intakes ( $Z$-score) of energy, protein and $\mathrm{Ca}$, physical activity ( $Z$-score of MET), use of vitamin supplements (yes/no), use of Ca supplements (yes/no), sex and Tanner stage (adolescents), and years since menopause (postmenopausal women). Starchy vegetables were excluded from the calculation of total fruit and vegetable intake in the above analyses.

A two-sided $P$ value less than 0.05 was considered as statistically significant. We used winsorization to replace outliers that were at least 3 SD away from the group mean with the next most extreme value, as the few outliers might extremely affect the mean values and the associations $^{(22)}$. All data analyses were conducted using the SPSS for Windows statistical software package version 13 (SPSS Inc., Chicago, IL, USA).

\section{Results}

\section{Participants' characteristics and dietary intakes}

Table 1 shows the general information of the participants, including age, body weight, height, BMI, age at menarche, years since menopause, physical activity, $\mathrm{Ca}$ and vitamin supplement use, and the summary (mean and SD) of BMD

Table 1 Characteristics of the study participants, Guangdong, China, July 2009 to May 2010

\begin{tabular}{|c|c|c|c|c|c|c|c|c|}
\hline \multirow[b]{2}{*}{ Variable } & \multicolumn{2}{|c|}{$\begin{array}{l}\text { Boys } \\
(n 110)\end{array}$} & \multicolumn{2}{|c|}{$\begin{array}{l}\text { Girls } \\
(n 112)\end{array}$} & \multicolumn{2}{|c|}{$\begin{array}{l}\text { Young women } \\
\qquad(n 371)\end{array}$} & \multicolumn{2}{|c|}{$\begin{array}{l}\text { Postmenopausal women } \\
\text { (n 333) }\end{array}$} \\
\hline & Mean or $\%$ & $\mathrm{SD}$ & Mean or $\%$ & SD & Mean or $\%$ & SD & Mean or \% & SD \\
\hline Age (years) & $12 \cdot 9$ & 0.4 & $12 \cdot 9$ & 0.4 & $27 \cdot 1$ & $2 \cdot 9$ & $57 \cdot 4$ & 3.9 \\
\hline Weight (kg) & $47 \cdot 7$ & $11 \cdot 6$ & $45 \cdot 4$ & $6 \cdot 2$ & $58 \cdot 7$ & $7 \cdot 9$ & $56 \cdot 0$ & $9 \cdot 0$ \\
\hline Height (cm) & $156 \cdot 8$ & $8 \cdot 6$ & $155 \cdot 3$ & $5 \cdot 0$ & $158 \cdot 3$ & $4 \cdot 7$ & $156 \cdot 0$ & $6 \cdot 0$ \\
\hline BMI $\left(\mathrm{kg} / \mathrm{m}^{2}\right)$ & $19 \cdot 2$ & $3 \cdot 5$ & $18 \cdot 8$ & $2 \cdot 5$ & $23 \cdot 4$ & $2 \cdot 9$ & $23 \cdot 1$ & $3 \cdot 1$ \\
\hline Age at menarche (years) & - & & $11 \cdot 4$ & $0 \cdot 8$ & $13 \cdot 5$ & $3 \cdot 2$ & $13 \cdot 9$ & $1 \cdot 7$ \\
\hline Years since menopause & - & & - & & - & & $7 \cdot 3$ & $4 \cdot 5$ \\
\hline Ca supplement use (\%) & $30 \cdot 9$ & & $26 \cdot 8$ & & $81 \cdot 9$ & & $30 \cdot 9$ & \\
\hline Vitamin supplement use (\%) & $19 \cdot 1$ & & $17 \cdot 9$ & & $62 \cdot 5$ & & $16 \cdot 8$ & \\
\hline Energy intake $(\mathrm{kJ} / \mathrm{d})$ & 6756 & 1703 & 8267 & 2691 & 9263 & 2444 & 6128 & 1536 \\
\hline Dietary Ca intake (mg/d) & 721 & 258 & 701 & 234 & 845 & 344 & 676 & 301 \\
\hline Physical activity (MET/d) & $36 \cdot 3$ & $3 \cdot 2$ & 35.9 & $2 \cdot 8$ & $33 \cdot 6$ & $4 \cdot 8$ & $34 \cdot 7$ & $5 \cdot 2$ \\
\hline \multicolumn{9}{|l|}{$\operatorname{BMD}\left(\mathrm{g} / \mathrm{cm}^{2}\right)$} \\
\hline Whole body & 0.954 & 0.069 & $1 \cdot 000$ & 0.081 & $1 \cdot 092$ & 0.068 & $1 \cdot 050$ & 0.090 \\
\hline Lumbar spine L1-L4 & 0.799 & $0 \cdot 113$ & 0.938 & 0.137 & $1 \cdot 082$ & $0 \cdot 117$ & 0.970 & $0 \cdot 144$ \\
\hline Total hip & 0.891 & $0 \cdot 116$ & 0.890 & $0 \cdot 115$ & 0.940 & 0.107 & 0.879 & 0.123 \\
\hline Femoral neck & 0.870 & 0.115 & 0.870 & 0.110 & 0.916 & 0.108 & 0.824 & 0.109 \\
\hline Femoral shaft & 0.995 & 0.144 & $1 \cdot 018$ & 0.143 & $1 \cdot 119$ & 0.136 & 1.059 & 0.149 \\
\hline Trochanter & 0.765 & 0.103 & 0.727 & 0.097 & 0.729 & 0.096 & 0.698 & $0 \cdot 104$ \\
\hline Ward's area & 0.814 & 0.118 & 0.791 & 0.135 & 0.836 & 0.130 & 0.652 & 0.125 \\
\hline
\end{tabular}

MET, metabolic equivalent for task; BMD, bone mineral density.

Data are presented as means and standard deviations or as percentages.

¥Cooking oil was not included in the calculation of energy intake due to poor accuracy. 
Table 2 Intakes of vegetables and fruit $(\mathrm{g} / \mathrm{d})$, and the percentage contribution of subtypes to total intake, among the study participants, Guangdong, China, July 2009 to May 2010

\begin{tabular}{|c|c|c|c|c|c|c|c|c|c|c|c|c|}
\hline & \multicolumn{3}{|c|}{$\begin{array}{l}\text { Boys } \\
(n 110)\end{array}$} & \multicolumn{3}{|c|}{$\begin{array}{l}\text { Girls } \\
(n 112)\end{array}$} & \multicolumn{3}{|c|}{$\begin{array}{l}\text { Young women } \\
\quad(n 371)\end{array}$} & \multicolumn{3}{|c|}{$\begin{array}{l}\text { Postmenopausal women } \\
\qquad(n \text { 333) }\end{array}$} \\
\hline & Mean & SD & $\%$ & Mean & SD & $\%$ & Mean & SD & $\%$ & Mean & SD & $\%$ \\
\hline \multicolumn{13}{|l|}{ Vegetable groups } \\
\hline Leafy vegetablesł & 200 & 119 & $65 \cdot 2$ & 181 & 77 & $63 \cdot 9$ & 150 & 126 & $43 \cdot 7$ & 243 & 124 & $54 \cdot 8$ \\
\hline $\begin{array}{l}\text { Melons§, carrot and radish, tomato, peppers, } \\
\text { and onion and garlic }\end{array}$ & 50 & 40 & $17 \cdot 2$ & 60 & 49 & $19 \cdot 9$ & 109 & 89 & $31 \cdot 5$ & 131 & 85 & $28 \cdot 6$ \\
\hline Starchy tubers $\|$ and fresh corn & 19 & 19 & $7 \cdot 0$ & 20 & 24 & $6 \cdot 8$ & 52 & 52 & $15 \cdot 7$ & 45 & 42 & $10 \cdot 0$ \\
\hline Fresh beans & 9 & 8 & $3 \cdot 1$ & 12 & 27 & $3 \cdot 7$ & 22 & 25 & $6 \cdot 6$ & 14 & 55 & $2 \cdot 9$ \\
\hline Mushrooms & 26 & 57 & $7 \cdot 5$ & 16 & 18 & $5 \cdot 7$ & 9 & 12 & $2 \cdot 5$ & 17 & 21 & $3 \cdot 8$ \\
\hline Total & 303 & 158 & 100 & 289 & 117 & 100 & 344 & 186 & 100 & 435 & 204 & 100 \\
\hline \multicolumn{13}{|l|}{ Fruit groups } \\
\hline Apple, pear, peach, pineapple, plum & 68 & 70 & $45 \cdot 8$ & 72 & 91 & $41 \cdot 6$ & 151 & 181 & $38 \cdot 3$ & 73 & 103 & $40 \cdot 3$ \\
\hline Orange, grapefruit, lemon & 41 & 72 & $23 \cdot 6$ & 53 & 78 & $26 \cdot 5$ & 72 & 103 & $19 \cdot 7$ & 35 & 45 & $19 \cdot 3$ \\
\hline Banana & 15 & 20 & $12 \cdot 9$ & 14 & 19 & $10 \cdot 0$ & 30 & 43 & $8 \cdot 2$ & 20 & 28 & $12 \cdot 0$ \\
\hline Grapes, lychee, longan & 11 & 23 & $7 \cdot 9$ & 17 & 31 & $9 \cdot 2$ & 42 & 61 & $11 \cdot 2$ & 19 & 42 & $10 \cdot 5$ \\
\hline Papaya, water melons, various muskmelons & 8 & 17 & $7 \cdot 9$ & 10 & 19 & $7 \cdot 1$ & 48 & 88 & $11 \cdot \overline{7}$ & 16 & 21 & $10 \cdot 7$ \\
\hline Mango, persimmon & 1 & 3 & $0 \cdot 8$ & 4 & 14 & $3 \cdot 2$ & 4 & 17 & 0.9 & 2 & 4 & $1 \cdot 3$ \\
\hline Durian and other fruits & 3 & 16 & $1 \cdot 1$ & 3 & 13 & $1 \cdot 6$ & 41 & 83 & $10 \cdot 0$ & 10 & 17 & 5.9 \\
\hline Total & 185 & 165 & 100 & 206 & 182 & 100 & 380 & 251 & 100 & 174 & 157 & 100 \\
\hline
\end{tabular}

łLeafy vegetables: pak choi, choi sum, lettuce, spinach, Chinese spinach, water spinach, Chinese kale, mustard, broccoli, cabbage, cauliflower, celery, etc. \$Melons: Chinese waxgourd, pumpkin, cucumber, towel gourd, bitter gourd, luffa-smooth loofah, etc.

IStarchy tubers: yam, potato, sweet potato, taro, lotus root, etc.

and dietary intakes of energy and Ca. Mean vegetable intake was 303, 289, 344 and $435 \mathrm{~g} / \mathrm{d}$ and mean fruit intake was $185,206,380$ and $174 \mathrm{~g} / \mathrm{d}$ in boys, girls, young women and postmenopausal women, respectively. About $40 \%$ of the fruit intake was from the group of apple, pear, peach, pineapple and plum, and $20 \%$ from the group of orange, grapefruit and lemon. About half of all vegetables consumed were leafy vegetables, followed by various vegetable melons, carrot and radish (Table 2).

\section{Association of fruit and vegetable intakes and bone mass in adolescents and adults}

In general, ANOVA showed that fruit and vegetable intakes were significantly and positively associated with BMD and BMC at the majority of the studied bone sites. Fruit intake had a much more significant association with BMD or BMC than did vegetable intake and the total intake of fruit and vegetables. BMD $Z$-score increased by $0 \cdot 30$ (or $2 \cdot 6 \%$ of the mean), $0 \cdot 25(3 \cdot 9 \%), 0 \cdot 27(3 \cdot 5 \%)$ and $0 \cdot 29(4 \cdot 0 \%)$, and BMC Z-score increased by $0 \cdot 44(7 \cdot 6 \%)$, $0 \cdot 31(7 \cdot 2 \%), 0 \cdot 44(7 \cdot 5 \%)$ and $0.36(5 \cdot 9 \%)$, at the total body, lumbar spine, total hip and femoral neck in participants belonging to the top tertile compared with the bottom tertile of fruit intake (all $P<0 \cdot 01$ ), respectively. Small differences in BMD Z-score $(0 \cdot 13-0 \cdot 19)$ and BMC $Z$-score $(0 \cdot 10-0 \cdot 18)$ were observed between the top and bottom tertiles of vegetable intake. The mean difference in BMD $Z$-score ranged from $0 \cdot 13$ to $0 \cdot 25$ and in BMC $Z$-score from $0 \cdot 20$ to $0 \cdot 35$ between the highest and lowest tertiles of total intake of fruit and vegetables (Table 3 ).

After adjustment for potential confounding factors, such as age, BMI, dietary intakes of energy, protein and Ca, physical activity, use of vitamin supplements, use of
Ca supplements and menopause status, significant associations between fruit intake and BMD/BMC remained, although the associations were slightly attenuated. The $P$ values for trend ranged between $<0 \cdot 001$ and $0 \cdot 002$. Mean differences in $Z$-score ranged between 0.22 and $0 \cdot 25$ (BMD) and $0 \cdot 25$ and $0 \cdot 34$ (BMC) between the top and bottom tertiles of fruit intake (all $P<0 \cdot 05$ ). However, only a marginally significant association between vegetable intake and total body $\operatorname{BMD}(P=0 \cdot 030)$ was observed. There was no significant association of vegetable intake with either BMD or BMC at any other bone site. The effect of total intake of fruit and vegetables on $\mathrm{BMD}$ and $\mathrm{BMC}$ was in the range between those of fruit and vegetable intake separately (Table 4).

\section{Association of fruit and vegetable intakes and bone mass in subgroups}

To explore the potential sensitive populations, we conducted subgroup-stratified analyses by age and sex groups. Among the four age and sex groups, boys had the strongest associations of total intake of fruit and vegetables with $\mathrm{BMD}$ and BMC, followed by girls and postmenopausal women. Multivariate regression analyses showed a marginally significant positive association of total intake of fruit and vegetables with BMD at the hip site in boys, at the trochanter in girls and at the whole body in postmenopausal women ( $P$ values: $0 \cdot 014-0 \cdot 081$ ), but no significant association was observed at all bone sites except for the whole body BMC $(P=0.043)$ in young women (Table 5$)$.

\section{Sensitivity analysis}

Almost the same results were observed when the original values of the outliers were included (data not shown). 
Table 3 Z-scores of BMD and BMC at various sites by fruit and vegetable intake tertiles of the study participants, Guangdong, China, July 2009 to May $2010 \ddagger$

\begin{tabular}{|c|c|c|c|c|c|c|c|c|c|c|}
\hline & \multicolumn{2}{|c|}{ Tertile 1 ( $n$ 307) } & \multicolumn{2}{|c|}{ Tertile 2 (n 310) } & \multicolumn{2}{|c|}{ Tertile 3 (n 309) } & \multicolumn{2}{|c|}{ Difference } & \multicolumn{2}{|c|}{ ANOVA } \\
\hline & Mean & SD & Mean & SD & Mean & SD & Abs. & $\%$ & $P$ diff. & $P$ trend \\
\hline \multicolumn{11}{|c|}{ By fruit intake } \\
\hline TB BMD & $-0 \cdot 150$ & 0.984 & 0.001 & $1 \cdot 009$ & $0 \cdot 149^{\star \star *}$ & 0.969 & $0 \cdot 30$ & $2 \cdot 6$ & $<0.001$ & $<0.001$ \\
\hline LS BMD & -0.134 & 0.972 & 0.021 & $1 \cdot 010$ & $0 \cdot 113^{\star \star}$ & 0.988 & 0.25 & 3.9 & 0.008 & 0.002 \\
\hline TH BMD & -0.129 & 0.979 & -0.008 & $1 \cdot 032$ & $0 \cdot 136^{\star *}$ & 0.955 & $0 \cdot 27$ & $3 \cdot 5$ & 0.004 & 0.001 \\
\hline FN BMD & $-0 \cdot 141$ & 0.958 & -0.005 & 0.965 & $0 \cdot 145^{\star *}$ & 1.039 & 0.29 & $4 \cdot 0$ & 0.002 & $<0.001$ \\
\hline TB BMC & -0.249 & 0.981 & $0 \cdot 059^{\star \star \star}$ & 0.986 & $0 \cdot 188^{\star \star \star}$ & 0.967 & 0.44 & $7 \cdot 6$ & $<0.001$ & $<0.001$ \\
\hline LS BMC & -0.177 & 0.951 & $0 \cdot 047^{*}$ & 0.995 & $0 \cdot 130^{\star \star *}$ & $1 \cdot 012$ & $0 \cdot 31$ & $7 \cdot 2$ & $<0.001$ & $<0.001$ \\
\hline TH BMC & -0.240 & 0.976 & $0.041^{* *}$ & 0.986 & $0 \cdot 197^{\star \star \star}$ & 0.974 & 0.44 & $7 \cdot 5$ & $<0.001$ & $<0.001$ \\
\hline FN BMC & -0.191 & 0.989 & $0.025^{\star \star}$ & 1.003 & $0 \cdot 165^{\star \star \star}$ & 0.960 & $0 \cdot 36$ & $5 \cdot 9$ & $<0.001$ & $<0.001$ \\
\hline \multicolumn{11}{|c|}{ By vegetable intake } \\
\hline TB BMD & -0.071 & 0.983 & -0.077 & $1 \cdot 025$ & $0 \cdot 147$ & 0.960 & $0 \cdot 22$ & 1.9 & 0.006 & 0.006 \\
\hline LS BMD & -0.022 & 0.931 & -0.052 & 1.078 & 0.075 & 0.966 & $0 \cdot 10$ & 1.5 & 0.253 & 0.225 \\
\hline TH BMD & -0.012 & 0.959 & -0.114 & $1 \cdot 046$ & $0 \cdot 126$ & 0.961 & $0 \cdot 14$ & $1 \cdot 8$ & 0.011 & 0.084 \\
\hline FN BMD & 0.003 & $1 \cdot 046$ & -0.097 & 0.969 & 0.095 & 0.960 & 0.09 & $1 \cdot 3$ & 0.056 & 0.252 \\
\hline TB BMC & -0.039 & 0.971 & -0.099 & $1 \cdot 038$ & $0 \cdot 138$ & 0.958 & $0 \cdot 18$ & $3 \cdot 1$ & 0.009 & 0.027 \\
\hline LS BMC & -0.017 & 0.994 & -0.067 & 1.007 & 0.084 & 0.979 & $0 \cdot 10$ & $2 \cdot 4$ & $0 \cdot 158$ & $0 \cdot 210$ \\
\hline TH BMC & -0.039 & 0.984 & $-0 \cdot 100$ & $1 \cdot 028$ & 0.138 & 0.955 & $0 \cdot 18$ & $3 \cdot 0$ & 0.009 & 0.027 \\
\hline FN BMC & -0.024 & $1 \cdot 003$ & -0.109 & 0.991 & $0 \cdot 133$ & 0.976 & $0 \cdot 16$ & $2 \cdot 6$ & 0.009 & 0.048 \\
\hline \multicolumn{11}{|c|}{ By total fruit and vegetable intake } \\
\hline TB BMD & $-0 \cdot 100$ & 0.977 & -0.052 & $1 \cdot 018$ & $0 \cdot 152^{* *}, \dagger$ & 0.972 & $0 \cdot 25$ & $2 \cdot 16$ & 0.004 & 0.002 \\
\hline LS BMD & -0.054 & 0.965 & -0.023 & $1 \cdot 040$ & 0.077 & 0.974 & $0 \cdot 13$ & $2 \cdot 09$ & 0.232 & $0 \cdot 103$ \\
\hline TH BMD & -0.094 & 0.977 & -0.025 & $1 \cdot 028$ & $0 \cdot 118^{*}$ & 0.968 & $0 \cdot 21$ & $2 \cdot 78$ & 0.027 & 0.008 \\
\hline FN BMD & -0.087 & 0.962 & -0.008 & $1 \cdot 057$ & 0.094 & 0.955 & $0 \cdot 18$ & $2 \cdot 55$ & 0.077 & 0.024 \\
\hline TB BMC & -0.148 & 0.999 & -0.059 & 0.976 & $0 \cdot 206^{* \star *}, \mathrm{tt}$ & 0.976 & $0 \cdot 35$ & $6 \cdot 13$ & $<0.001$ & $<0.001$ \\
\hline LS BMC & -0.065 & 0.960 & -0.068 & $1 \cdot 027$ & $0 \cdot 134^{\star}, t$ & 0.983 & $0 \cdot 20$ & $4 \cdot 64$ & 0.016 & 0.013 \\
\hline TH BMC & $-0 \cdot 160$ & 0.992 & -0.022 & $1 \cdot 003$ & $0 \cdot 179^{\star \star \star}, \dagger$ & 0.960 & $0 \cdot 34$ & $5 \cdot 84$ & $<0.001$ & $<0.001$ \\
\hline FN BMC & -0.116 & $1 \cdot 000$ & -0.032 & $1 \cdot 013$ & $0 \cdot 148^{\star \star \star}$ & 0.953 & 0.26 & $4 \cdot 34$ & 0.003 & $<0.001$ \\
\hline
\end{tabular}

BMD, bone mineral density; BMC, bone mineral content; TB, total body; LS, lumbar spine (L1-L4); TH, left total hip; FN, femoral neck.

Mean values were significantly different from those of tertile $1:{ }^{\star} P<0 \cdot 05,{ }^{\star \star} P<0 \cdot 01,{ }^{\star \star \star} P<0.001$.

Mean values were significantly different from those of tertile 2: $+P<0.05,++P<0.01$.

$\ddagger$ Original BMD and BMC were converted to standard normal Z-score stratified by subgroups of girls, boys, young women and postmenopausal women.

$\S$ Difference between tertile 3 and tertile 1: Abs., absolute mean difference (tertile 3 - tertile 1); \%, relative difference compared with the mean BMD

or $\mathrm{BMC}, \%=[(\mathrm{Abs} . \times \mathrm{SD}) /$ Mean $] \times 100 \%$, where Mean and SD are the mean and SD of BMD or BMC.

\section{Discussion}

In the present cross-sectional study containing adolescents, young women and postmenopausal women, we found a significant positive association between fruit intake and BMD and BMC at all studied bone sites and between vegetable intake and total body BMD. A previous study estimated that a $1 \mathrm{SD}$ decrease in total hip BMD was associated with an $85 \%$ (95\% CI 70, 101\%) increase in the risk of total osteoporotic hip fractures ${ }^{(23)}$. According to this estimation, an increase in BMD of $0 \cdot 22 \mathrm{SD}$ at the total hip would result in a 19\% decrease in the risk of hip fracture in the top compared with the bottom tertile of fruit intake in our population. These results suggest that greater intake of fruit and vegetables may be beneficial to improve bone mass.

Several small studies have examined the association between fruit and vegetable intake and bone measurements and yielded weak positive or null effects. Prynne et $a l^{(7)}$ found that greater fruit and vegetable intake was associated with higher BMD and BMC at the whole body and spine, and BMC at the hip, in both 111 boys (mean age 16.8 years) and 101 girls (mean age $17 \cdot 4$ years). A similar positive association of fruit and vegetable consumption with heel BMD was found by McGartland et al. ${ }^{(24)}$ in 378 girls (but not in 324 boys) aged 12 years. In a 7 -year follow-up study, Vatanparast et $a l^{(9)}$ found that every additional serving of fruit and vegetables was associated with an increase of 5.4 (SE 1.3) $\mathrm{g}$ in total body BMC accrual in eighty-five boys aged 8-20 years, but no significant effect was observed in sixty-seven girls of the same age. Tylavsky et $a l^{(8)}$ found that fruit and vegetable intake was a significant independent predictor of bone area but not BMD or BMC in fifty-six girls aged 8-13 years. Our findings are consistent with the previous results. However, due to the limitations of study design and small sample size in previous studies, more prospective large studies are needed to confirm the effect in adolescents in future.

New et al. ${ }^{(5)}$ first reported the positive association of fruit and vegetable consumption with bone mass in a cross-sectional study in 1997. Similar positive associations between fruit and vegetable intake and BMD, BMC or low fracture rate were also observed in elderly men and women of the Framingham cohort $^{(6)}$, in middle-aged postmenopausal women in Hong Kong ${ }^{(10)}$, in a populationbased survey of mainland Chinese men and women ${ }^{(25)}$, and in old women in the $\mathrm{UK}^{(7)}$. However, inconsistent results 
Table 4 Covariable-adjusted of BMD and BMC at various sites by fruit and vegetable intake tertiles of the study participants, Guangdong, China, July 2009 to May $2010 \ddagger$

\begin{tabular}{|c|c|c|c|c|c|c|c|c|c|c|}
\hline & \multicolumn{2}{|c|}{ Tertile 1} & \multicolumn{2}{|c|}{ Tertile 2} & \multicolumn{2}{|c|}{ Tertile 3} & \multicolumn{2}{|c|}{ Difference } & \multicolumn{2}{|c|}{ ANCOVAll } \\
\hline & Mean & SE & Mean & SE & Mean & SE & Abs. & $\%$ & $P$ diff. & $P$ trend \\
\hline \multicolumn{11}{|c|}{ By fruit intake } \\
\hline TB BMD & -0.114 & 0.054 & -0.023 & 0.052 & $0 \cdot 133^{\star *}$ & 0.055 & 0.25 & $2 \cdot 1$ & 0.007 & 0.002 \\
\hline LS BMD & -0.110 & 0.056 & -0.003 & 0.054 & $0.111^{*}$ & 0.057 & 0.22 & 3.5 & 0.027 & 0.007 \\
\hline TH BMD & $-0 \cdot 100$ & 0.055 & -0.014 & 0.053 & $0.132^{*}$ & 0.056 & 0.23 & $3 \cdot 0$ & 0.014 & 0.004 \\
\hline FN BMD & -0.110 & 0.055 & -0.032 & 0.054 & $0 \cdot 138^{\star \star}$ & 0.056 & 0.25 & $3 \cdot 5$ & 0.008 & 0.002 \\
\hline TB BMC & $-0 \cdot 181$ & 0.050 & $0.030^{\star *}$ & 0.049 & $0 \cdot 146^{\star \star \star}$ & 0.051 & 0.33 & $5 \cdot 7$ & $<0.001$ & $<0.001$ \\
\hline LS BMC & -0.138 & 0.055 & 0.025 & 0.054 & $0 \cdot 111^{\star \star}$ & 0.056 & 0.25 & $5 \cdot 8$ & 0.008 & 0.002 \\
\hline TH BMC & -0.179 & 0.052 & $0.013^{*}$ & 0.051 & $0 \cdot 162^{\star \star \star}$ & 0.053 & 0.34 & $5 \cdot 9$ & $<0.001$ & $<0.001$ \\
\hline FN BMC & -0.144 & 0.053 & -0.006 & 0.052 & $0 \cdot 144^{\star \star \star}$ & 0.054 & 0.29 & $4 \cdot 7$ & 0.001 & $<0.001$ \\
\hline \multicolumn{11}{|c|}{ By vegetable intake } \\
\hline TB BMD & -0.067 & 0.056 & -0.061 & 0.052 & $0 \cdot 123^{*}$ & 0.056 & $0 \cdot 19$ & $1 \cdot 6$ & 0.030 & 0.024 \\
\hline LS BMD & -0.025 & 0.058 & -0.030 & 0.054 & 0.053 & 0.058 & 0.08 & $1 \cdot 2$ & 0.546 & 0.373 \\
\hline TH BMD & 0.004 & 0.057 & -0.071 & 0.053 & 0.086 & 0.057 & 0.08 & $1 \cdot 1$ & $0 \cdot 129$ & 0.334 \\
\hline FN BMD & -0.001 & 0.055 & -0.078 & 0.051 & 0.056 & 0.055 & 0.06 & 0.8 & 0.195 & 0.058 \\
\hline TB BMC & -0.013 & 0.053 & -0.071 & 0.049 & 0.082 & 0.053 & $0 \cdot 10$ & $1 \cdot 6$ & $0 \cdot 109$ & 0.229 \\
\hline LS BMC & 0.003 & 0.057 & -0.048 & 0.054 & 0.049 & 0.057 & 0.05 & $1 \cdot 1$ & 0.467 & 0.594 \\
\hline TH BMC & -0.001 & 0.055 & -0.067 & 0.051 & 0.065 & 0.055 & 0.07 & $1 \cdot 1$ & $0 \cdot 211$ & $0.05 \varepsilon$ \\
\hline FN BMC & 0.001 & 0.055 & -0.084 & 0.052 & 0.077 & 0.055 & 0.08 & $1 \cdot 3$ & 0.102 & 0.036 \\
\hline \multicolumn{11}{|c|}{ By total fruit and vegetable intake } \\
\hline TB BMD & -0.080 & 0.056 & -0.035 & 0.052 & $0 \cdot 111$ & 0.056 & $0 \cdot 19$ & $1 \cdot 6$ & 0.057 & 0.024 \\
\hline LS BMD & -0.035 & 0.058 & -0.011 & 0.054 & 0.044 & 0.058 & 0.08 & $1 \cdot 3$ & 0.655 & 0.373 \\
\hline TH BMD & -0.076 & 0.057 & 0.008 & 0.053 & 0.085 & 0.057 & $0 \cdot 16$ & $2 \cdot 1$ & $0 \cdot 171$ & 0.060 \\
\hline FN BMD & -0.065 & 0.058 & 0.007 & 0.054 & 0.055 & 0.057 & $0 \cdot 12$ & $1 \cdot 7$ & 0.375 & $0 \cdot 166$ \\
\hline TB BMC & -0.091 & 0.053 & -0.034 & 0.049 & $0 \cdot 121^{*}$ & 0.053 & 0.21 & $3 \cdot 7$ & 0.021 & 0.008 \\
\hline LS BMC & -0.023 & 0.058 & -0.055 & 0.054 & 0.076 & 0.058 & $0 \cdot 10$ & $2 \cdot 3$ & $0 \cdot 254$ & 0.259 \\
\hline TH BMC & -0.107 & 0.055 & 0.003 & 0.051 & $0 \cdot 100^{\star}$ & 0.055 & 0.21 & 3.6 & 0.044 & 0.012 \\
\hline FN BMC & -0.075 & 0.056 & -0.015 & 0.052 & 0.085 & 0.056 & 0.16 & $2 \cdot 6$ & 0.153 & 0.056 \\
\hline
\end{tabular}

BMD, bone mineral density; BMC, bone mineral content; ANCOVA, analysis of covariance; TB, total body; LS, lumbar spine (L1-L4); TH, left total hip; FN, femoral neck.

Mean values were significantly different from those of tertile $1:{ }^{\star} P<0.05,{ }^{* \star} P<0.01,{ }^{* \star *} P<0.001$.

¥Original BMD and BMC were converted to standard normal Z-score stratified by subgroups of girls, boys, young women and postmenopausal women. $\S$ Difference between tertile 3 and tertile 1: Abs., absolute mean difference (tertile $3-$ tertile 1); \%, relative difference compared with the mean BMD or $\mathrm{BMC}, \%=[($ Abs. $\times$ SD $) /$ Mean $] \times 100 \%$, where Mean and SD are the mean and SD of BMD or BMC.

॥Covariates adjusted for in the multivariate model: age (years), BMI (Z-score), dietary intakes (Z-score) of energy, protein and Ca, physical activity (Z-score of metabolic equivalent for task), use of vitamin supplements (yes/no), use of Ca supplements (yes/no), sex and Tanner stage (adolescents), menopause status (yes/no) and years since menopause (menopausal women).

Table 5 Regression coefficients of the association between total fruit and vegetable intake and bone mass in subgroups by sex and age, Guangdong, China, July 2009 to May 2010

\begin{tabular}{|c|c|c|c|c|c|c|c|c|}
\hline & \multicolumn{2}{|c|}{$\begin{array}{l}\text { Girls } \\
(n 112)\end{array}$} & \multicolumn{2}{|c|}{$\begin{array}{l}\text { Boys } \\
(n \text { 110) }\end{array}$} & \multicolumn{2}{|c|}{$\begin{array}{l}\text { Young women } \\
\quad(n 371)\end{array}$} & \multicolumn{2}{|c|}{$\begin{array}{l}\text { Postmenopausal women } \\
\text { ( }(n 333)\end{array}$} \\
\hline & $\beta_{1}$ & $\beta_{2}$ & $\beta_{1}$ & $\beta_{2}$ & $\beta_{1}$ & $\beta_{2}$ & $\beta_{1}$ & $\beta_{2}$ \\
\hline \multicolumn{9}{|c|}{ Bone mineral density } \\
\hline Whole body & $0 \cdot 170^{(\star)}$ & $0 \cdot 140$ & $0.203^{\star}$ & 0.131 & 0.064 & 0.068 & $0 \cdot 144^{\star \star}$ & $0 \cdot 105^{(*)}$ \\
\hline Spine & 0.070 & 0.054 & 0.084 & -0.006 & 0.014 & 0.007 & $0 \cdot 108^{*}$ & 0.088 \\
\hline Total hip & $0 \cdot 113$ & 0.094 & $0 \cdot 240^{*}$ & $0.195^{\star}$ & 0.047 & 0.083 & $0 \cdot 110^{\star}$ & 0.059 \\
\hline Femoral neck & 0.075 & 0.050 & $0 \cdot 192^{*}$ & $0 \cdot 139$ & 0.026 & 0.059 & $0 \cdot 130^{*}$ & 0.078 \\
\hline Trochanter & $0 \cdot 184^{(*)}$ & $0 \cdot 201^{(\star)}$ & $0 \cdot 230^{\star}$ & $0 \cdot 190^{\star}$ & 0.067 & 0.097 & $0 \cdot 119^{*}$ & 0.049 \\
\hline Femoral shaft & 0.094 & 0.068 & $0 \cdot 269^{\star \star}$ & $0.222^{*}$ & 0.043 & 0.081 & $0 \cdot 105^{(*)}$ & 0.056 \\
\hline Ward's area & 0.075 & 0.090 & $0 \cdot 221^{*}$ & $0 \cdot 197^{\star}$ & 0.032 & 0.038 & $0 \cdot 107^{\star}$ & 0.064 \\
\hline \multicolumn{9}{|c|}{ Bone mineral content } \\
\hline Whole body & $0 \cdot 174^{(*)}$ & 0.097 & $0 \cdot 218^{\star}$ & 0.098 & $0 \cdot 111^{*}$ & $0 \cdot 119^{*}$ & $0 \cdot 197^{\star \star \star}$ & $0 \cdot 107^{(*)}$ \\
\hline Spine & $0 \cdot 123$ & $0 \cdot 121$ & $0 \cdot 121$ & 0.016 & 0.011 & -0.013 & $0 \cdot 163^{\star \star}$ & $0 \cdot 114^{(*)}$ \\
\hline Total hip & $0 \cdot 163^{(*)}$ & $0 \cdot 118$ & $0.239^{\star}$ & $0 \cdot 139^{(*)}$ & 0.073 & 0.089 & $0 \cdot 205^{\star \star \star}$ & $0.098^{(*)}$ \\
\hline Femoral neck & $0 \cdot 119$ & 0.088 & $0 \cdot 198^{*}$ & $0 \cdot 110$ & 0.033 & 0.060 & $0 \cdot 180^{* * *}$ & 0.087 \\
\hline Trochanter & $0 \cdot 193^{*}$ & $0 \cdot 169$ & $0 \cdot 244^{*}$ & $0 \cdot 152^{(*)}$ & 0.084 & 0.077 & $0 \cdot 170$ & 0.062 \\
\hline Femoral shaft & $0 \cdot 135$ & 0.077 & $0.234^{*}$ & $0 \cdot 134^{(*)}$ & 0.059 & 0.094 & $0 \cdot 174^{* *}$ & 0.070 \\
\hline Ward's area & $0 \cdot 124$ & $0 \cdot 127$ & $0 \cdot 215^{\star}$ & $0 \cdot 137$ & 0.009 & 0.007 & $0 \cdot 186^{\star \star \star}$ & 0.085 \\
\hline
\end{tabular}

$\beta_{1}$ and $\beta_{2}$, univariate and multivariate regression coefficients, unit: Z-score/Z-score.

Covariates adjusted for in multivariate model: age (years), BMI (Z-score), dietary intakes (Z-score) of energy, protein and Ca, physical activity (Z-score of metabolic equivalent for task), use of vitamin supplements (yes/no), use of Ca supplements (yes/no), sex and Tanner stage (adolescents), and years since menopause (postmenopausal women).

Significance of the regression coefficient: $\left.{ }^{\star}\right) P<0.1,{ }^{\star} P<0.05,{ }^{\star \star} P<0.01,{ }^{\star \star \star} P<0.001$. 
(null effect) were also found in several studies or subpopulations $^{(6,7,11)}$.

To our knowledge, the present study is the first one assessing the association of fruit and vegetable intakes with bone measurements in postpartum women. Only a marginally significant association was found for total body $\mathrm{BMC}$ in the multivariate regression analyses in this group. Up to date, very limited data have been published on young women. Prynne et al. ${ }^{(7)}$ reported non-significant associations between vegetable and fruit intake and BMD or BMC at the total body, lumbar spine, total hip and neck in women aged 23-37 years. It is unclear whether the null association with BMD was due to the specificity of age, pregnancy, greater changes in dietary intakes due to pregnancy, or just because of the weak or null effect of fruit and vegetables in this population.

In general, the above studies showed a weak beneficial effect of higher intake of fruit and vegetables on bone measurements. In contrast to the previous results, the present study observed significant positive associations between fruit intake and BMD and BMC at several bone sites even adjustment for potential confounders in adolescents, young and postmenopausal women combined, and in some of the studied bone sites among the four subgroups. The reasons for the inconsistent results found in different studies remain unclear. The weak effect of fruit and vegetables, small study size, large random error in the assessment of long-term intake of fruit and vegetables, and other environmental and genetic heterogeneity in different populations might partially explain the inconsistent results. However, due to the limitations of study design and small sample size in previous studies, more prospective large studies are needed to confirm the effect in future.

The mechanisms whereby vegetables and fruit affect bone health have been explored in previous publications and focused mainly on two aspects. The first one, called the acid-base hypothesis, postulates that acid load is, in part, buffered by bone mineral, leading to bone dissolution and reduced bone density ${ }^{(26,27)}$. Diets high in acid-forming components (including several amino acids in protein foods, $\mathrm{P}$ and $\mathrm{Cl}$ ) and low in base-forming components ( $\mathrm{K}, \mathrm{Ca}, \mathrm{Mg}$ and vitamin $\mathrm{C}$ ) lead to a higher dietary acid load ${ }^{(28)}$. Vegetables and fruit, as a good source of alkaline-forming components, could neutralize the calciuric effects of acids derived from the diet ${ }^{(29,30)}$. Moreover, some literature documents that the above alkaline-forming cations have an independent impact on improving Ca balance ${ }^{(31,32)}$ and bone health ${ }^{(5,6,33)}$. The second aspect is that vegetables and fruit might affect bone health via the roles of antioxidant vitamins, such as vitamin $\mathrm{C}^{(34,35)}$ and vitamin $\mathrm{K}^{(36,37)}$. However, after adjusting for the potential influence of these nutrients, vitamin D and fibre, McGartland et al. ${ }^{(24)}$ proved that the positive association between fruit intake and heel BMD in the 12-year-old girls remained. It is possible that the observed association between fruit and BMD might be related to another mechanism other than the two mentioned. Other compounds found in vegetables and fruit, such as phyto-oestrogens and phytochemicals, might be taken into account ${ }^{(38)}$. However, these mechanisms cannot explain the more pronounced favourable effect of fruit than of vegetables on bone mass observed in the present and previous studies ${ }^{(7,10)}$. It is well established that $\mathrm{Na}$ plays a key role in Ca metabolism ${ }^{(39,40)}$. Vegetables are consumed mainly in cooked form in Chinese populations. Therefore, the higher intake of $\mathrm{Na}$ consumed with vegetables might counteract the favourable effect of vegetables as compared with fruit, which tend to be consumed fresh.

\section{Study validity and limitations}

There were several potential limitations in the present study. First, the participants were volunteers, not a nationally representative sample. We could not exclude potential volunteer bias. Next, the study was crosssectional in design. The validity of the causal relationship between fruit and vegetable consumption and bone mass depends mainly on the stability of fruit and vegetable intakes. Since it is unlikely to increase consumption of fruit and vegetables due to good bone mass, any changes in fruit and vegetable intake would attenuate the association. Therefore, we might not overestimate the strength of the association. Furthermore, we could not adjust for the influence of vitamin D because of very poor accuracy in the assessment of vitamin D intake using the FFQ, due to limited inclusion of vitamin D-enriched food items. However, plenty sunlight in Guangzhou in southern China would decrease the contribution of vitamin D from the diet. Also, we could not precisely adjust for supplemental $\mathrm{Ca}$ because most participants could not accurately report the dosage. Another limitation was the relatively small sample size in each sub-population: although we had a total of 926 participants, we did not have sufficient power to detect weak associations in the subgroups.

Nevertheless, the exposures we examined here - dietary factors - permitted elucidation of the associations of fruit and vegetable consumption with bone health owing to their relatively stable nature, particularly in postmenopausal women, as discussed previously ${ }^{(10)}$. Dietary intake was assessed using a validated FFQ with good validity and reliability in the assessment of habitual intake of fruit and vegetables in this population ${ }^{(20)}$, and we adjusted for a number of important covariates in the multivariate analysis.

\section{Conclusions}

Fruit and vegetable consumption was positively associated with bone mass in adolescents, young women and 
postmenopausal women combined. More benefits were observed in boys and postmenopausal women than in girls and young women. Fruits had a much stronger association with bone mass than vegetables. Our findings add to the existing evidence that fruit and vegetables may have a bone sparing effect.

\section{Acknowledgements}

The study was jointly supported by the 11th Five Year Key Programs for Science and Technology Development of China (no. 2008BAI58B02) and the National Natural Science Foundation of China (no. 30872100, 81072299). There are no conflicts of interest. Y.-X.S. and Y.-M.C. obtained the grants, had full access to all of the data and take responsibility for the integrity of the data and the accuracy of the data analysis. Y.-M.C., Y.-X.S. and Z.-W.H. were responsible for the study concept and design; J.-J.L., R.-Q.W., X.-M.M., Z.-Q.Z. and Z.L. acquired the data; Y.-M.C., J.-J.L. and Y.-X.S. analysed and interpreted the data; J.-J.L. and Y.-M.C. drafted the manuscript; Y.-M.C., Y.-X.S. and Z.-W.Z. critically revised the manuscript for important intellectual content.

\section{References}

1. Holroyd C, Cooper C \& Dennison E (2008) Epidemiology of osteoporosis. Best Pract Res Clin Endocrinol Metab 22, 671-685.

2. Lane NE (2006) Epidemiology, etiology, and diagnosis of osteoporosis. Am J Obstet Gynecol 194, 2 Suppl., S3-S11.

3. New SA, Bonjour JP, New SA et al. (2003) Nutritional Aspects of Bone Health. Cambridge: The Royal Society of Chemistry.

4. Chen YM \& Ho SC (2009) Fruit, vegetables, and bone health. In Bioactive Foods in Promoting Health, pp. 173-194 [RR Watson and VR Preedy, editors]. Oxford: Academic Press.

5. New SA, Bolton-Smith C, Grubb DA et al. (1997) Nutritional influences on bone mineral density: a cross-sectional study in premenopausal women. Am J Clin Nutr 65, 1831-1839.

6. Tucker KL, Hannan MT, Chen H et al. (1999) Potassium, magnesium, and fruit and vegetable intakes are associated with greater bone mineral density in elderly men and women. Am J Clin Nutr 69, 727-736.

7. Prynne CJ, Mishra GD, O'Connell MA et al. (2006) Fruit and vegetable intakes and bone mineral status: a cross sectional study in 5 age and sex cohorts. Am J Clin Nutr $\mathbf{8 3}$, 1420-1428.

8. Tylavsky FA, Holliday K, Danish R et al. (2004) Fruit and vegetable intakes are an independent predictor of bone size in early pubertal children. Am J Clin Nutr 79, 311-317.

9. Vatanparast H, Baxter-Jones A, Faulkner RA et al. (2005) Positive effects of vegetable and fruit consumption and calcium intake on bone mineral accrual in boys during growth from childhood to adolescence: the University of Saskatchewan Pediatric Bone Mineral Accrual Study. Am J Clin Nutr 82, 700-706.

10. Chen YM, Ho SC \& Woo JL (2006) Greater fruit and vegetable intake is associated with increased bone mass among postmenopausal Chinese women. Br J Nutr 96, 745-751.
11. Kaptoge S, Welch A, McTaggart A et al. (2003) Effects of dietary nutrients and food groups on bone loss from the proximal femur in men and women in the 7th and 8th decades of age. Osteoporos Int 14, 418-428.

12. Hamidi M, Boucher BA, Cheung AM et al. (2011) Fruit and vegetable intake and bone health in women aged 45 years and over: a systematic review. Osteoporos Int 22, 1681-1693.

13. Rizzoli R \& Bonjour JP (1999) Determinants of peak bone mass and mechanisms of bone loss. Osteoporos Int $\mathbf{9}$, Suppl. 2, S17-S23.

14. Sowers M (1996) Pregnancy and lactation as risk factors for subsequent bone loss and osteoporosis. J Bone Miner Res 11, 1052-1060.

15. Givens MH \& Macy IC (1933) The chemical composition of the human fetus. $J$ Biol Chem 102, 7-17.

16. Nilas L \& Christiansen C (1988) Rates of bone loss in normal women: evidence of accelerated trabecular bone loss after the menopause. Eur J Clin Invest 18, 529-534.

17. Leung SS, Ho SC, Woo J et al. (1997) Hong Kong Adult Dietary Survey. Hong Kong: The Chinese University of Hong Kong.

18. Zhai F \& Yang X (2006) 2002 National Nutrition and Health Survey in Chinese Residents: Part II. Beijing: People's Medical Publishing House.

19. Djousse L, Arnett DK, Coon H et al. (2004) Fruit and vegetable consumption and LDL cholesterol: the National Heart, Lung, and Blood Institute Family Heart Study. Am J Clin Nutr 79, 213-217.

20. Zhang CX \& Ho SC (2009) Validity and reproducibility of a food frequency questionnaire among Chinese women in Guangdong province. Asia Pac J Clin Nutr 18, 240-250.

21. Yang YX, Wang GY \& Pan XC (2002) China Food Composition 2002. Beijing: Peking University Medical Press.

22. Howell DC (1987) Statistical Methods for Psychology, 2nd ed. Boston, MA: Duxbury Press.

23. Leslie WD, Lix LM, Tsang JF et al. (2007) Single-site vs multisite bone density measurement for fracture prediction. Arch Intern Med 167, 1641-1647.

24. McGartland CP, Robson PJ, Murray LJ et al. (2004) Fruit and vegetable consumption and bone mineral density: the Northern Ireland Young Hearts Project. Am J Clin Nutr 80, 1019-1023.

25. Zalloua PA, Hsu YH, Terwedow H et al. (2007) Impact of seafood and fruit consumption on bone mineral density. Maturitas 56, 1-11.

26. Barzel US (1995) The skeleton as an ion exchange system: implications for the role of acid-base imbalance in the genesis of osteoporosis. J Bone Miner Res 10, 1431-1436.

27. Green J \& Kleeman CR (1991) The role of bone in the regulation of systemic acid-base balance. Contrib Nephrol 91, 61-76.

28. Bushinsky DA (2001) Acid-base imbalance and the skeleton. Eur J Nutr 40, 238-244.

29. Buclin T, Cosma M, Appenzeller M et al. (2001) Diet acids and alkalis influence calcium retention in bone. Osteoporos Int 12, 493-499.

30. Tucker KL, Hannan MT \& Kiel DP (2001) The acid-base hypothesis: diet and bone in the Framingham Osteoporosis Study. Eur J Nutr 40, 231-237.

31. Lemann J Jr, Pleuss JA \& Gray RW (1993) Potassium causes calcium retention in healthy adults. J Nutr 123, 1623-1626.

32. Sebastian A, Harris ST, Ottaway JH et al. (1994) Improved mineral balance and skeletal metabolism in postmenopausal women treated with potassium bicarbonate. $N$ Engl J Med 330, 1776-1781.

33. Macdonald HM, New SA, Golden MH et al. (2004) Nutritional associations with bone loss during the menopausal transition: evidence of a beneficial effect of calcium, alcohol, and fruit and vegetable nutrients and of a detrimental effect of fatty acids. Am J Clin Nutr 79, 155-165. 
34. Morton DJ, Barrett-Connor EL \& Schneider DL (2001) Vitamin C supplement use and bone mineral density in postmenopausal women. J Bone Miner Res 16, 135-140.

35. Hall SL \& Greendale GA (1998) The relation of dietary vitamin $\mathrm{C}$ intake to bone mineral density: results from the PEPI study. Calcif Tissue Int 63, 183-189.

36. Binkley NC \& Suttie JW (1995) Vitamin K nutrition and osteoporosis. J Nutr 125, 1812-1821.

37. Booth SL, Broe KE, Gagnon DR et al. (2003) Vitamin K intake and bone mineral density in women and men. $A m J$ Clin Nutr 77, 512-516.
38. Tobe H, Muraki Y, Kitamura K et al. (1997) Bone resorption inhibitors from hop extract. Biosci Biotechnol Biochem 61, 158-159.

39. Ho SC, Chen YM, Woo JL et al. (2001) Sodium is the leading dietary factor associated with urinary calcium excretion in Hong Kong Chinese adults. Osteoporos Int 12, 723-731.

40. Teucher B, Dainty JR, Spinks CA et al. (2008) Sodium and bone health: impact of moderately high and low salt intakes on calcium metabolism in postmenopausal women. J Bone Miner Res 23, 1477-1485. 